Research Paper

\title{
SPPS Resins Impact the PNA-Syntheses' Improvement
}

\author{
Rüdiger Pipkorn ${ }^{1 凶}$, Stephan Rawer ${ }^{2}$, Manfred Wiessler ${ }^{3}$, Waldemar Waldeck ${ }^{4}$, Mario Koch ${ }^{1}$, Hans Her- \\ mann Schrenk ${ }^{3}$, Klaus Braun ${ }^{3}$
}

1. German Cancer Research Center, Peptide Synthesis Core Facility, INF 280, D-69120 Heidelberg, Germany;

2. Life Technologies, Frankfurter Strasse 129, D-64293 Darmstadt, Germany;

3. German Cancer Research Center, Medical Physics in Radiology, INF 580, D-69120 Heidelberg, Germany;

4. German Cancer Research Center, Biophysics of Macromolecules, INF 280, D-69120 Heidelberg, Germany.

$\bowtie$ Corresponding author: E-mail: r.pipkorn@dkfz.de.

() Ivyspring International Publisher. This is an open-access article distributed under the terms of the Creative Commons License (http://creativecommons.org/ licenses/by-nc-nd/3.0/). Reproduction is permitted for personal, noncommercial use, provided that the article is in whole, unmodified, and properly cited.

Received: 2012.10.12; Accepted: 2012.12.19; Published: 2013.02.13

\begin{abstract}
The personalized medicine, also documented as "individualized medicine", is an effective and therapeutic approach. It is designed to treat the disease of the individual patient whose precise differential gene expression profile is well known. The trend in the biomedical and biophysical research shows important consequences for the pharmaceutical drug and diagnostics research. It requires a high variability in the design and safety of target-specific pharmacologically active molecules and diagnostic components for imaging of metabolic processes. A key technology which may fulfill the highest demands during synthesis of these individual drugs and diagnostics is the solid phase synthesis which is congenial to automated manufacturing. Additionally the choice of tools like resins and reagents is pivotal to synthesize drugs and diagnostics in high quality and yields. Here we demonstrate the solid phase synthesis effects dependent on the choice of resin and of the deprotection agent.
\end{abstract}

Key words: peptide nucleic acid (PNA); solid phase peptide synthesis (SPPS).

\section{Introduction}

The increasingly expanding biomedical and biophysical research areas trace back to the human genome project (HGP) founded and started in 1990 as a manhood's big challenge for providing scientific findings to better understand biochemistry, molecular biology and medical sciences [1]. In the year 2001 the human's genome decryption was first documented by the International Human Genome Sequencing Consortium and by Greg Venter's founded Celera Corporation $[2,3]$ simultaneously. With the release in 2003 of the genome's complete decoding in 2003, the HUGO was considered as finished [4,5]. It was then taken as the basis for the development of new diagnostic tools [6-8] and therapeutic approaches $[9,10]$ with a previously unreached precision in sensitivity and sensibility. This led to the Gene Ontology Anno- tation (GOA) project and the proteome [11, 12]. Also important is on the combination of both which describes the new expanding research field in the development of theranostic tools [13] enabling a successful pharmacotherapy with a minimum of adverse reactions, realizing a perfect fit to the patient's differential gene expression profile.. Due to the lack of stability of natural DNA and RNA against nucleases their use as a drug is not possible till now, and modifications are inevitable. Derivatives like peptide nucleic acids (PNAs) however, are not a substrate for the cell immanent enzymes and therefore they are resistant, highly sensitive and specific tools for antisense strategies [14-16] and can be applied both in cancer diagnostics and in therapy [23-25]. To increase their efficiency further they can be conjugated with 
cell penetrating peptides (CPP) and peptide-based sequences for subcellular targeting [17-19] and are individually designed by solid phase peptide synthesis (SPPS) methodologies. This is carried out by coupling of building blocks combined with protection group chemistry [20-22]. Despite the improvement in the PNA syntheses, high quality PNAs' syntheses remain a challenge in ligation and deprotection chemistry. The success of synthesis strongly depends on different parameters, like activator's quality and deproctection kinetics which also correlate with the length of the PNA SPPS polymer. Modifications of the solid phase PNA synthesis's methods like micro wave [26] and the use of suitable deprotection reagents, like piperidine and pyrrolidine [27] which optimize yield and quality, were established and documented. It became increasingly apparent, that the choice of resin matrices [28] with physical properties especially for a high quality PNA synthesis is pivotal to a considerable extent and additional investigations in the resin development are required [29]. Here we report how we synthesized a PNA (see Figure 5) targeted to the translation initiation region which is part of the complementary coding sequence of the human c-myc Exon II [30]. We compared, analyzed and optimized the synthesis strategy for forthcoming functional PNA studies dealing with the cell cycle behavior, apoptosis, alterations of the cell phenotype and differential gene expression.

\section{Chemical Procedure}

The synthesis of the human c-myc specific PNA TACGGGGAGTTGCAA-NH $\mathrm{N}_{2}$ shown in Figure 5, was performed on the ABI synthesizer 433A (Applied Biosystems, Foster City, USA). We used 9-fluorenylmethoxycarbonyl (Fmoc)-building blocks with blocked side chains of Adenine A, Cytosine C, and Guanine $G$ by benzhydroxylcarbonyl (Bhoc) groups. The syntheses were performed in a $5 \mu \mathrm{mol}$ scale on a H-Rink-Amide-ChemMatrix ${ }^{\circledR}$ resin (PCAS BioMatrix, Saint-Jean-sur-Richelieu, Canada) loading $0.52 \mathrm{mmol} / \mathrm{g}$ and on a TentaGel® R RAM high swell resin (RAPP Polymers, Tuebingen, Germany) loading $0.62 \mathrm{mmol} / \mathrm{g}$. In the first step the Fmoc-groups were cleaved with $20 \%$ piperidine in $N, N^{\prime}$-dimethylformamide (DMF) and $20 \%$ pyrrolidine in $\mathrm{N}$-methylpyrrolidone for $10 \mathrm{~min}$ at $20^{\circ} \mathrm{C}$. After that, the resin was washed 5 times with DMF. The coupling reaction was performed with 2-(1H-7-azabenzotriazole-1-yl)-1,1,3,3-tetramethyl uronium hexafluorophosphate (HATU) and $N, N^{\prime}$-diisopropylethylamine (DIPEA) for $40 \mathrm{~min}$. After the coupling all residual free amino groups were capped with acetic acid anhydride in DIPEA (1eq:2eq) in DMF and the resin was washed with DMF. At the end of the synthesis the $\mathrm{N}$-terminal protecting group was removed with piperidine or pyrrolidine respectively and the reaction product was finally cleaved from the resin with TFA (95\%) and scavanger triisopropylethylsilane/water $(2.5 \% / 2.5 \%)$ for $2.5 \mathrm{~h}$ at room temperature. The PNA product was precipitated in diethylether and subsequently lyophilized. The crude material was characterized with analytical HPLC on a Kromasil 100-5 $\mu$ m C 18 reverse phase column $(30 \times 250 \mathrm{~mm})$ using an eluent of $0.1 \%$ trifluoro acetic acid in water (A) and $80 \%$ acetonitrile in water (B). The PNA product was eluted with a successive linear gradient of $10 \% \mathrm{~B}$ to $80 \% \mathrm{~B}$ in $30 \mathrm{~min}$ at a flow rate of $1 \mathrm{ml} / \mathrm{min}$. (Figure 1 and Figure 2) and mass spectrometry (ESI-MS, Finnigan $^{\text {TM }}$ TSQ 7000) (Figure 3).

The chemical formula is $\mathrm{C}_{163} \mathrm{H}_{201} \mathrm{~N}_{93} \mathrm{O}_{44}$; exact mass: 4164.63; molecular weight: 4166.93; found mass: 4166.3. The nucleobase sequences derived from human-HSMMYCC GenBank AC NO.: X00364).

\section{Results and Discussion}

The solid phase peptide synthesis (SPPS) introduced by Merrifield is considered as the key technology in the automatized technique for the synthesis of functional peptides as well as for DNA derivatives like the peptide nucleic acids based on amino acids and peptide nucleic acid building blocks. Whereas at the beginning of the "SPPS age" time and efforts were immense, the progress in the synthesis' development led to reaction products with high puritiy and yield. The use of different modifications like microwaves [31,32] and ultrasound [33] resulted in a clear diminishment of the time rate in the reaction steps and resulted in simultaneously improvement of the quality. The resin acts as the solid phase platform originally described as "Merrifield-Resin" [34, 35]. Its enormous advantage is shown in the following data which highlight different aspects of a PNA SPPS. The diagrams (left \& right) document the HPLC analysis (Figure 1 and 2) and the corresponding mass (Figure 3) of the PNA product. It was exemplarily synthesized by SPPS dependent on the resin chosen [22] either TentaGel ${ }^{\circledR}$ R RAM high swell Rapp Polymers (Figure 1) or H-Rink Amide-ChemMatrix ${ }^{\circledR}$ Polymer (Figure 2) and the basicity of the protection reagent.

The HPLC diagrams in Figure 1 and in Figure 2 show the peaks of the PNA synthesis products synthesized on TentaGel® R RAM high swell Rapp Polymer and H-Rink-Amide-ChemMatrix ${ }^{\circledR}$ Resin as a solid phase. The higher number of peaks in the diagrams after using the piperidine-step (left diagrams) indicates a higher number of truncated products. 

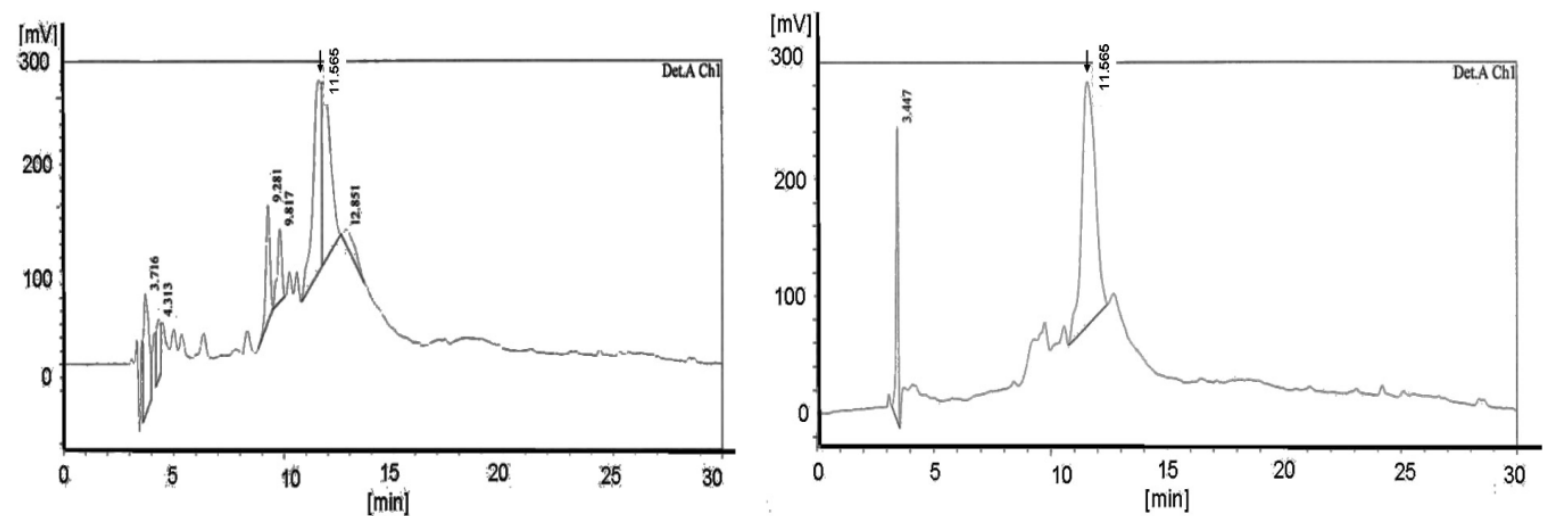

Figure I. Shows the HPLC diagram of the c-myc PNA synthesized on the peptide ABI synthesizer 433A equipped with the special deprotection module with fixed deprotection time. The left picture shows the TentaGelß R RAM high swell Rapp Polymers [loading $0.62 \mathrm{mmol} / \mathrm{g}$ ] deprotected with piperidine and the right picture exhibits the diagram of the pyrrolidine experiment (detection $\mathrm{Ch} / / 210 \mathrm{~nm}$ ). The yields are $6.0 \mathrm{mg}(28.8 \%)$ deprotected with piperidine and, with pyrrolidine $8.9 \mathrm{mg}(42.8 \%)$. The product peaks are shown at II.48 in the left and at II.565 in the right diagram. The left picture reveals the higher number of peaks compared to the right picture.
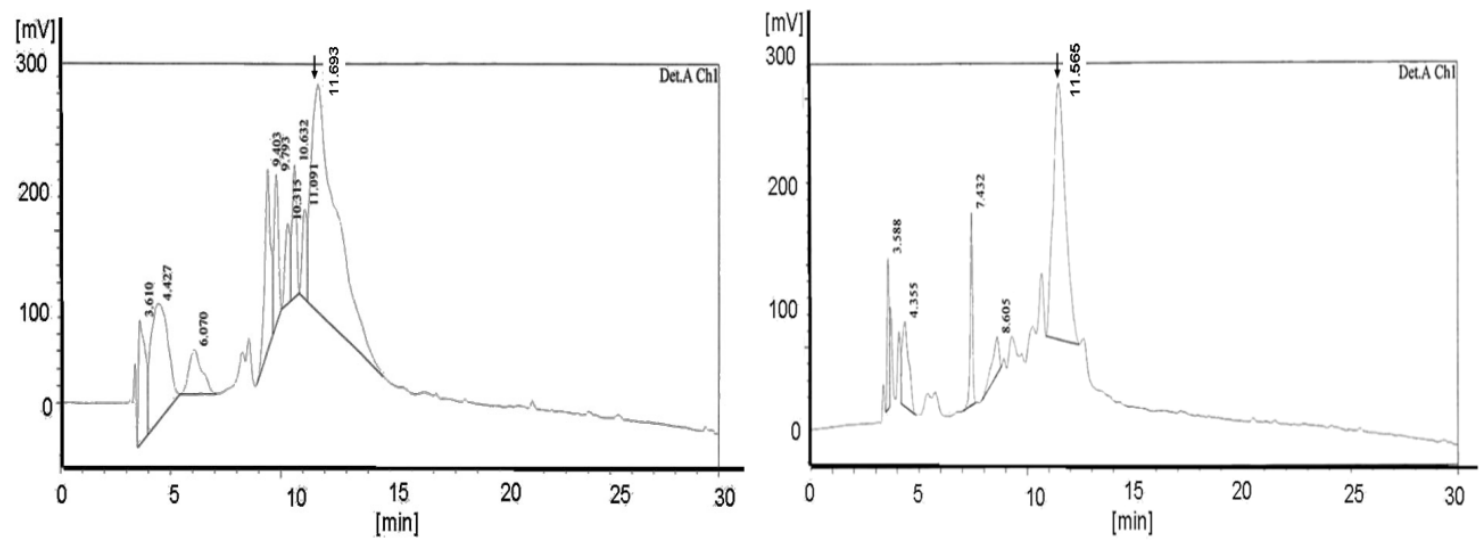

Figure 2. Also shows the graphs of the HPLC chromatogram of the c-myc PNA synthesized on the peptide synthesizer 433A equipped with the special deprotection module with fixed deprotection time. Here the left side reveals the H-Rink-Amide-ChemMatrix ${ }^{\circ}$ Resin [loading $\left.0.52 \mathrm{mmol} / \mathrm{g}\right]$ deprotected with piperidine and the right picture exhibit the diagram of the pyrrolidine experiment. (detection A Ch2 /280 nm). The yields are $5.5 \mathrm{mg}(26.4 \%$ ) deprotected with piperidine and, with pyrrolidine $7.8 \mathrm{mg}(37.5 \%)$. The product peaks are shown at II.693 in the left and at II.565 in the right diagram. The left picture displays more peaks than the right picture.

The ESI-MS diagrams in Figure 3 show the correct mass peaks after deprotection with pyrrolidine but independent from the used resins. More or less conspicuous but mentionable is the detection of the fivefold loaded $[\mathrm{M}+5 \mathrm{H}]^{5+}$ substance peak in the TentaGel® R RAM high swell Rapp Polymer representing diagram (right picture). The slight differences of the purities could be explained by the resins' different spatial patterns and surface characteristics which influence the syntheses: the TentaGel® R RAM high swell Rapp Polymer synthesis occurs spacer-mediated, whereas the synthesis runs directly at the ChemMatrix ${ }^{\circledR}$ Resin's backbone.

Furthermore, the graphs (Figure $4 \mathrm{~A}$ and B) highlight the discrepancies of the dissociated PNA building blocks as a function of the deprotection potential.
Since the liberated fluorenyl group is a chromophore, a deprotection by Fmoc can be monitored by UV absorbance of the fractions, a strategy which is employed in automated synthesizers. In the chart diagrams the bars represent the extent of the UV absorption at $301 \mathrm{~nm}$ of the separated fluorenyl groups. If a middle bar (as shown in B) occurs, a third deprotection step is carried out by the synthesizer's program routinely.

As shown in the left diagrams in the part A and B of Figure 4, we observed a more efficient deprotection behavior by pyrrolidine as a cleavage agent. Whereas one cleavage step was here sufficient, the use of piperidine as agent required three deprotection steps at all purines and also at the thymine. Additionally, the TentaGel® R RAM high swell resin seems to be more suitable for the deprotection steps during the PNA synthesis. 

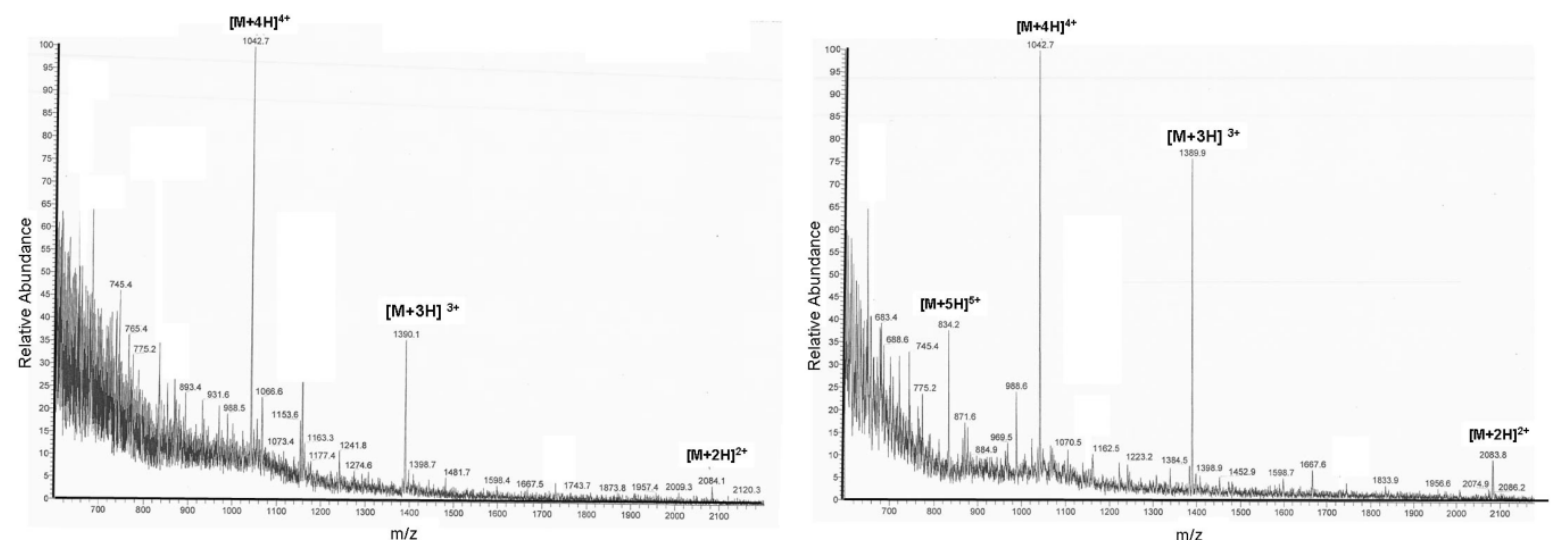

Figure 3. Shows the ESI-MS diagrams of the c-myc PNA. The left picture describes the H-Rink-Amide-ChemMatrix® Resin deprotected with pyrrolidine and the right picture depicts the diagram of the reaction product synthesized with the TentaGel $\mathbb{R}$ R RAM high swell Rapp Polymer under identical deprotection conditions.

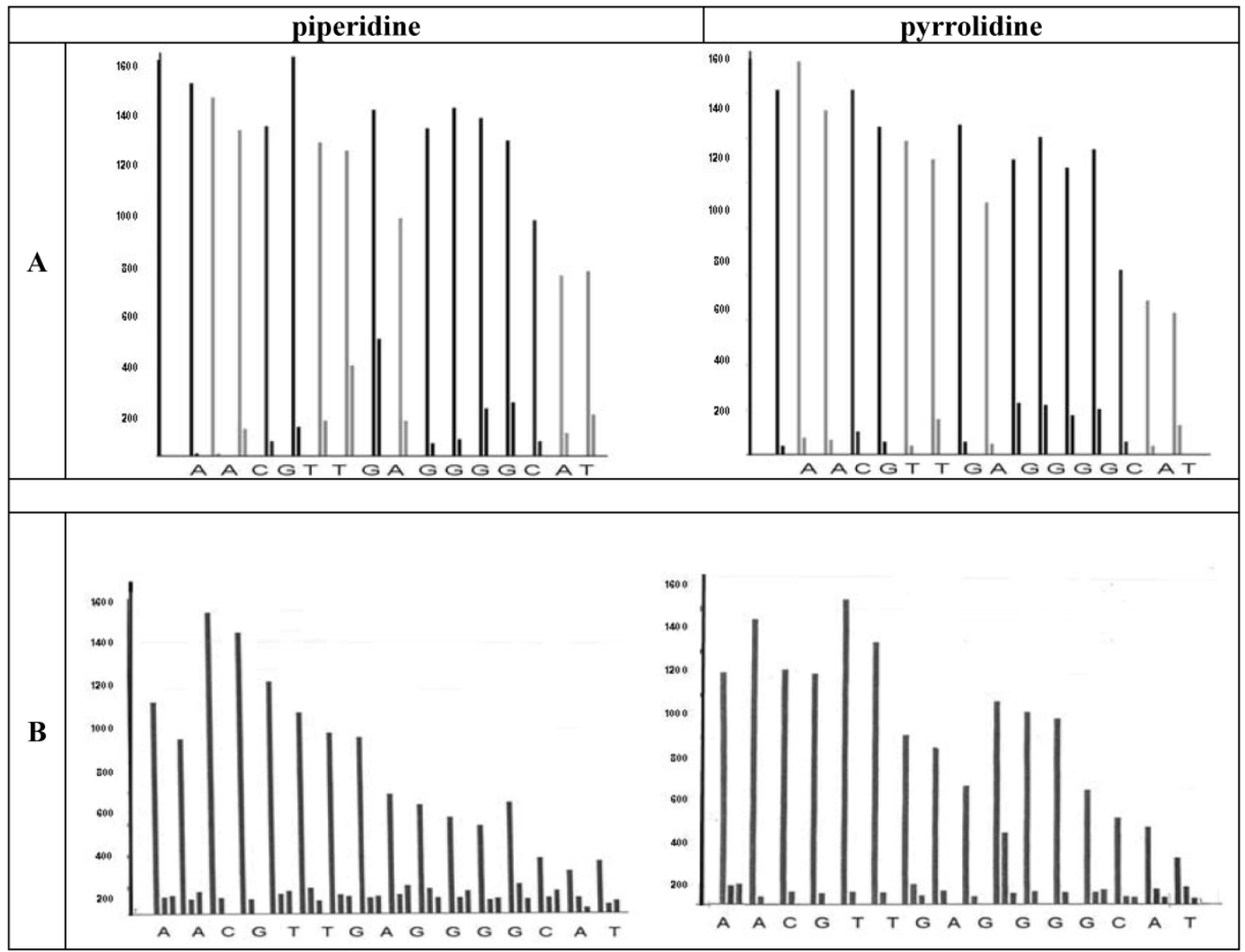

Figure 4. Visualizes the deprotection in every coupling step (left bars) and shows a better performance of pyrrolidine (right diagrams in the parts A and B). This is compared to piperidine in the final step. Each measurement was collected after a base treatment of 2.5 minutes. The upper part (A) shows the TentaGel ${ }^{\circledR}$ R RAM high swell Rapp Polymers and the lower part illustrates the H-Rink-Amide-ChemMatrix ${ }^{\circ}$ Resin bars (B). The products after the deprotection by piperidine are shown in the left column whereas the right column of the figure represents the bars of the pyrrolidine deprotected molecules. The height of the bars represents the amount of the Fmoc-group removed. The apparatus follows a cut off line $5 \%$ in front of the first bar. As soon as the second bar is lower then the adjusted value the program continoues, if not, a further deprotection is carried out. 


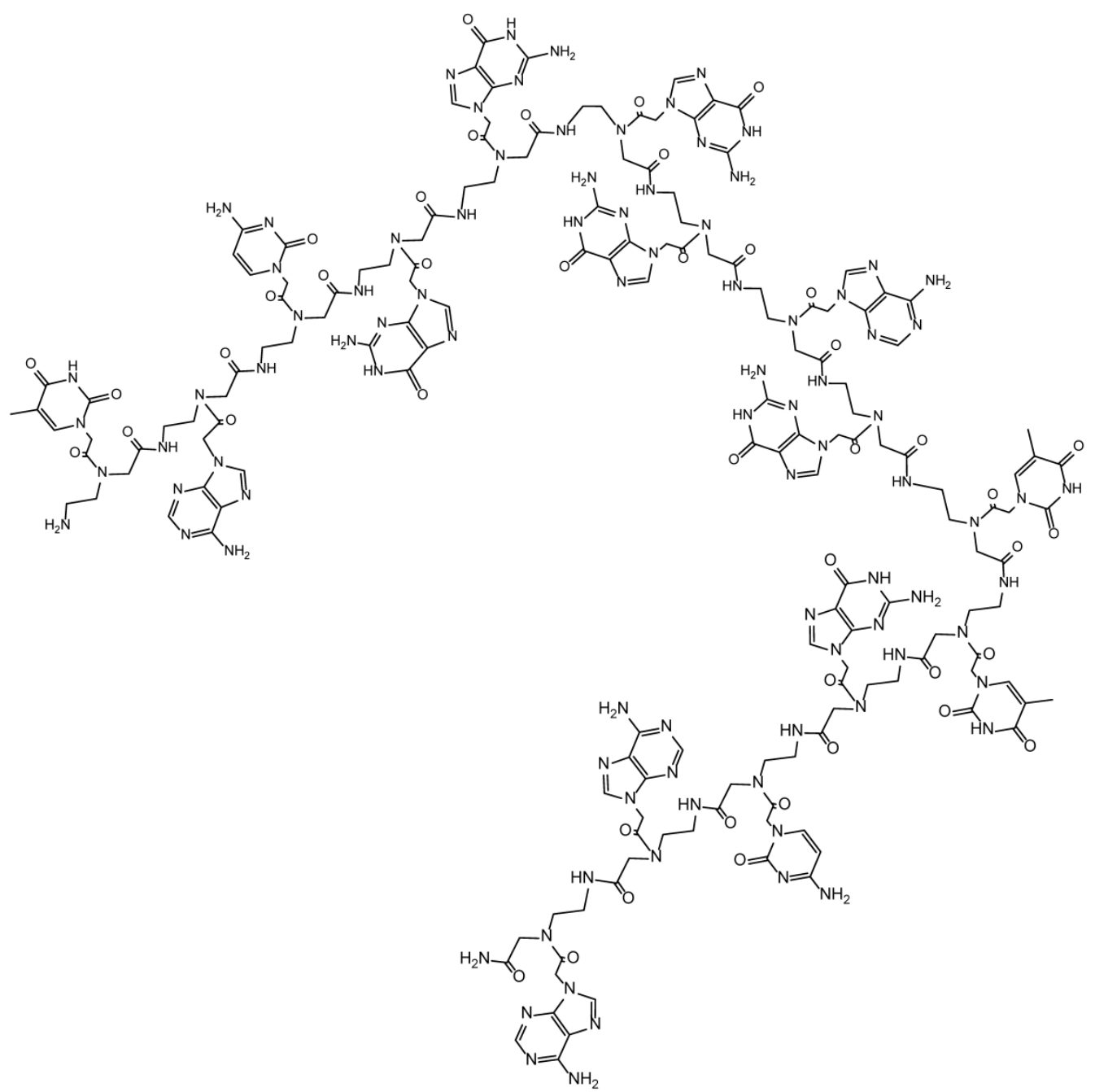

Figure 5. Illustrates a schematized structure of the peptide nucleic acid with the nucleobase sequence TACGGGGAGTTGCAA complementary to the human c-myc RNA Exon II (GenBank AC No.: X00364) [37].

With this experience we could achieve the best reaction product's purity on the TentaGel ${ }^{\circledR} \mathrm{R}$ RAM high swell resin with pyrrolidine as cleaving reagent. This result can be explained with the different physical properties of the TentaGel ${ }^{\circledR}$ R RAM high swell resin and the ChemMatrix resin. Namely, in the first case we performed the synthesis on a spacer and in the second case the synthesis occurred on the backbone of the resin and these properties gave rise to different swelling conditions [36].

\section{Conclusion}

Modern drugs consist of combined peptide-based functional modules with delivery and targeting properties. They are designed for use as a cargo of genetic material [38, 39], highly pharmacologically active substances like temozolomide (TMZ) $[40,41]$ or components for imaging of morphologic structures and metabolic processes in PET, SPECT [42], MRT
[43], and CT [44] as well as for optical imaging (OI) [45-48]. In case of theranostic agents [13, 49-51] both groups of cargos (therapeutic and diagnostic) may be combined and a monitoring of the therapeutic success is much easier. The efficacy of the delivery and the specificity of the targeting allow a successful therapy and medical diagnosis by application of drastically reduced doses resulting in minimized adverse reactions which then would lead to discontinuation of the therapy. The criteria for therapeutic and diagnostic use of these new conjugates pose highest requirements on the synthesis as well as on optimized ligation procedures [52-55]. The SPPS can be considered as an excellent technology and the choice of appropriate resins and deprotection chemicals is indispensable.

\section{Acknowledgments}

This work was partially supported by Deutsche 
Krebshilfe, D-53004 Bonn; Grant Number: 1066335.

\section{Competing Interests}

The authors have declared that no competing interest exists.

\section{References}

1. Sinsheimer RL. Human genome initiative. Science. 1990; 249: 1359.

2. Venter JC, Adams MD, Myers EW, Li PW, Mural RJ, Sutton GG, Smith HO, Yandell M, Evans CA, Holt RA, et al. The sequence of the human genome. Science. 2001; 291: 1304.

3. Lander ES, Linton LM, Birren B, Nusbaum C, Zody MC, Baldwin J, Devon K, Dewar K, Doyle M, FitzHugh W, et al. Initial sequencing and analysis of the human genome. Nature. 2001; 409: 860-921.

4. Little J, Khoury MJ, Bradley L, Clyne M, Gwinn M, Lin B, Lindegren ML, Yoon $\mathrm{P}$. The human genome project is complete. How do we develop a handle for the pump? Am J Epidemiol. 2003; 157: 667-73.

5. Abu-Amero K. Human genetics information on the Web. J R Soc Promot Health. 2003; 123: 102-4.

6. Lau TK, Leung TN. Genetic screening and diagnosis. Curr Opin Obstet Gynecol. 2005; 17: 163-9.

7. Csako G. Present and future of rapid and/or high-throughput methods for nucleic acid testing. Clin Chim Acta. 2006; 363: 6-31.

8. Hoffman M, Arnoldi C, Chuang I. The clinical bioinformatics ontology: a curated semantic network utilizing RefSeq information. Pac Symp Biocomput. 2005;:139-50.

9. Shastry BS. Genetic diversity and new therapeutic concepts. J Hum Genet. 2005; 50: 321-8.

10. Komaroff AL, Labaer J. Health for life. Genomic medicine: the science speeds up. Newsweek. 2005; 146: 57.

11. Camon E, Magrane M, Barrell D, Binns D, Fleischmann W, Kersey P, Mulder N, Oinn T, Maslen J, Cox A, et al. The Gene Ontology Annotation (GOA) project: implementation of GO in SWISS-PROT, TrEMBL, and InterPro. Genome Res. 2003; 13: 662-72.

12. Romero P, Wagg J, Green ML, Kaiser D, Krummenacker M, Karp PD. Computational prediction of human metabolic pathways from the complete human genome. Genome Biol. 2005; 6: R2.

13. Wiessler M, Hennrich U, Pipkorn R, Waldeck W, Cao L, Peter J, Ehemann V, Semmler W, Lammers T, Braun K. Theranostic cRGD-BioShuttle Constructs Containing Temozolomide- and Cy7 For NIR-Imaging and Therapy. Theranostics. 2011; 1: 381-94.

14. Nielsen PE, Egholm M, Berg RH, Buchardt O. Sequence-selective recognition of DNA by strand displacement with a thymine-substituted polyamide. Science. 1991; 254: 1497-500.

15. Nielsen PE. Peptide nucleic acid (PNA) - From DNA recognition to antisense and DNA structure. Biophys Chem. 1997; 68: 103-8.

16. Demidov VV, Potaman VN, Frank Kamenetskii MD, Egholm M, Buchard O, Sonnichsen SH, Nielsen PE. Stability of peptide nucleic acids in human serum and cellular extracts. Biochem Pharmacol. 1994; 48: 1310-3.

17. Derossi D, Chassaing G, Prochiantz A. Trojan peptides: the penetratin system for intracellular delivery. Tr Cell Biol. 1998; 8: 84-7.

18. Lindgren M, Hallbrink M, Prochiantz A, Langel U. Cell-penetrating peptides. Trends Pharmacol Sci. 2000; 21: 99-103.

19. Braun K, Peschke P, Pipkorn R, Lampel S, Wachsmuth M, Waldeck W, Friedrich E, Debus J. A biological transporter for the delivery of peptide nucleic acids (PNAs) to the nuclear compartment of living cells. J Mol Biol. 2002; 318: 237-43.

20. Merrifield RB. Solid Phase Peptide Synthesis. I The Synthesis of a Tetrapeptide. J Americ Chem Soc. 1963; 85: 2149-54.

21. Carpino LA, Han GY. The 9-Fluorenylmethoxycarbonyl Amino-Protecting Group. J ORG CHEM. 1972; 37: 3404-9.

22. Amblard M, Fehrentz JA, Martinez J, Subra G. Methods and Protocols of modern solid phase peptide synthesis. Molecular Biotechnology. 2006; 33: 239-54.

23. Pipkorn R, Waldeck W, Braun K. Synthesis and application of functional peptides as cell nucleus-directed molecules in the treatment of malignant diseases. J Mol Recognit. 2003; 16: 240-7.

24. Pipkorn R, Dunsch L, Wiessler M, Waldeck W, Braun K. A rare earth endo-Nitrite-Cluster-Fullerene-Conjugate useful as an intravital Contrast Agent in MRT? Biopolymers. 2011; 96: 506.

25. Pipkorn R, Wiessler M, Waldeck W, Koch M, Braun K. Functionalized PNA Backbone Building Blocks Eligible for Diels-Alder Click Chemistry in Molecular Imaging. Cell Penetrating Peptides 31EPS CPP satellite meeting. 2010;: 10-1.
26. Pipkorn R, Wiessler M, Waldeck W, Hennrich U, Nokihara K, Beining M, Braun K. Improved Synthesis Strategy for Peptide Nucleic Acids (PNA) appropriate for Cell-specific Fluorescence Imaging. Int J Med Sci. 2012; 9: $1-10$.

27. Pipkorn R, Rawer S, and Braun K. Optimization of the PNA-synthesis using different bases for Fmoc-deprotection. Proceedings 32th European Peptide Symposium. Megaron 2012. Athens, Greece. 2012.

28. Pugh KC, York EJ, Stewart JM. Effects of resin swelling and substitution on solid phase synthesis. Int J Pept Protein Res. 1992; 40: 208-13.

29. Rawer S, Roeder R, and Henklein P. Proceedings 29th European Peptide Symposium. Peptides $2006 ;: 780$.

30. Heckl S, Pipkorn R, Waldeck W, Spring H, Jenne J, Der Lieth CW, Corban-Wilhelm H, Debus J, Braun K. Intracellular Visualization of Prostate Cancer Using Magnetic Resonance Imaging. Cancer Res. 2003; 63: 4766-72.

31. Loffredo C, Assuncao NA, Gerhardt J, Miranda MT. Microwave-assisted solid-phase peptide synthesis at 60 degrees C: alternative conditions with low enantiomerization. J Pept Sci. 2009; 15: 808-17.

32. Murray JK, Aral J, Miranda LP. Solid-phase peptide synthesis using microwave irradiation. Methods Mol Biol. 2011; 716: 73-88.

33. Adamson R, Gregson S, Shaw G. New applications of sporopollenin as a solid phase support for peptide synthesis and the use of sonic agitation. Int J Pept Protein Res. 1983; 22: 560-4.

34. Scotchler J, Lozier R, Robinson AB. Cleavage of single amino acid residues from Merrifield resin with hydrogen chloride and hydrogen fluoride. J Org Chem. 1970; 35: 3151-2.

35. Yang X, Lin H, Lu W, Wang D. Compatibility Study of Merrifield Linker in Fmoc Strategy Peptide Synthesis. Protein Pept Lett. 2013;20(2):140-5.

36. Rapp W, Beyermann M, Henklein P, Pipkorn R, Rawer S, and Rothemund S. Preventing failure in difficult sequences: An improved resin matrix, its properties and application. Proceedings 32th European Peptide Symposium. Megaron 2012. Athens, Greece. 2012.

37. Leonetti C, Biroccio A, D'Angelo C, Semple SC, Scarsella M, Zupi G. Therapeutic integration of c-myc and bcl-2 antisense molecules with docetaxel in a preclinical model of hormone-refractory prostate cancer. Prostate. 2007; 67: 1475-85.

38. Braun K, von BL, Pipkorn R, Ehemann V, Jenne J, Spring H, Debus J, Didinger B, Rittgen W, Waldeck W. BioShuttle-mediated plasmid transfer. Int J Med Sci. 2007; 4: 267-77.

39. Pipkorn R, Waldeck W, Braun K. The SPPs of bacterial addressed peptides and PNAs overcoming the resistance against antibiotics. Biopolymers. 2005; 80: 528 .

40. Waldeck W, Wiessler M, Ehemann V, Pipkorn R, Spring H, Debus J, Didinger B, Mueller G, Langowski J, Braun K. TMZ-BioShuttle--a reformulated temozolomide. Int J Med Sci. 2008; 5: 273-84.

41. Braun K, Wiessler M, Ehemann V, Pipkorn R, Spring H, Debus J, Didinger B, Koch M, Muller G, Waldeck W. Treatment of glioblastoma multiforme cells with temozolomide-BioShuttle ligated by the inverse Diels-Alder ligation chemistry. Drug Des Devel Ther. 2009; 2: 289-301.

42. Rahmim A, Zaidi H. PET versus SPECT: strengths, limitations and challenges. Nucl Med Commun. 2008; 29: 193-207.

43. Braun K, Dunsch L, Pipkorn R, Bock M, Baeuerle T, Yang S, Waldeck W, Wiessler M. Gain of a 500-fold sensitivity on an intravital MR contrast agent based on an endohedral gadolinium-cluster-fullerene-conjugate: a new chance in cancer diagnostics. Int J Med Sci. 2010; 7: 136-46.

44. Bartling SH, Budjan J, Aviv H, Haneder S, Kraenzlin B, Michaely H, Margel S, Diehl S, Semmler W, Gretz N, et al. First Multimodal Embolization Particles Visible on X-ray/Computed Tomography and Magnetic Resonance Imaging. Invest Radiol. 2011 Mar;46(3):178-86.

45. Braun K, Wiessler M, Pipkorn R, Ehemann V, Bauerle T, Fleischhacker H, Muller G, Lorenz P, Waldeck W. A cyclic-RGD-BioShuttle functionalized with TMZ by DARinv "Click Chemistry" targeted to alphavbeta3 integrin for therapy. Int J Med Sci. 2010; 7: 326-39.

46. Cao L, Peter J. Bayesian reconstruction strategy of fluorescence-mediated tomography using an integrated SPECT-CT-OT system. Phys Med Biol. 2010; 55: 2693-708.

47. Braun K, Beining M, Wiessler M, Lammers T, Pipkorn R, Hennrich U, Nokihara K, Semmler W, Debus J, Waldeck W. BioShuttle Mobility in Living Cells Studied with High-Resolution FCS \& CLSM Methodologies. Int J Med Sci. 2012; 9: 339-52.

48. Pipkorn R, Wiessler M, Dunsch L, Bock M, Debus J, Waldeck W, Braun K. Rare Earth Endo-Nitrite-Cluster-Fullerenes functionalized with the BioShuttle Carrier - Candidates for MR-Contrast Agents? Proceedings of the 4th CCS Symposium. 2011;: 85-91.

49. Lammers T, Aime S, Hennink WE, Storm G, Kiessling F. Theranostic Nanomedicines. Acc Chem Res. 2011; 44: 1029-38.

50. Lammers T, Kiessling F, Hennink WE, Storm G. Nanotheranostics and image-guided drug delivery: current concepts and future directions. Mol Pharm. 2010; 7: 1899-912. 
51. Tan M, Lu Z-R. Integrin targeted MR imaging . Theranostics. 2011; 1: 83-101.

52. Kolb HC, Sharpless KB. The growing impact of click chemistry on drug discovery. Drug Discov Today. 2003; 8: 1128-37.

53. Wiessler M., Kliem C., Lorenz P, Mueller E, and Fleischhacker $H$. Ligation reaction based on the Diels Alder Reaction with invers electron demand. EU Patent 2006; [EP 06012 414.6].

54. Wiessler M, Waldeck W, Pipkorn R, Kliem C, Lorenz P, Fleischhacker H, Hafner M, Braun K. Extension of the PNA world by functionalized PNA monomers eligible candidates for inverse Diels Alder Click Chemistry. Int J Med Sci. 2010; 7: 213-23.

55. Wiessler M, Waldeck W, Kliem C, Pipkorn R, Braun K. The Diels-Alder-reaction with inverse-electron-demand, a very efficient versatile click-reaction concept for proper ligation of variable molecular partners. Int J Med Sci. 2009; 7: 19-28. 